\title{
Sacral Neuromodulation in Children with Neurogenic Bladder Dysfunction
}

\author{
Natália MB Bezerra ${ }^{1}$, Luana CFL Leal ${ }^{2}$, Gentil GF Filho ${ }^{2,3}$, Lorena Andreoli ${ }^{1}$, Lilian L Lisboa ${ }^{2,3}$, Edgard Morya ${ }^{1,3 *}$, \\ Hougelle Simplício ${ }^{1,3,4,5}$ \\ ${ }^{1}$ Edmond and Lily Safra International Institute of Neuroscience, Santos Dumont Institute, Brazil \\ ${ }^{2}$ Physiotherapy, Federal University of Rio Grande do Norte, Brazil \\ ${ }^{3}$ Anita Garibaldi Center for Education and Research in Health, Santos Dumont Institute, Brazil \\ ${ }^{4}$ Health Sciences School, State University of Rio Grande do Norte, Brazil \\ ${ }^{5}$ Brain Research and Development co., Brazil \\ *Corresponding author: Edgard Morya, Edmond and Lily Safra International Institute of Neuroscience, Santos Dumont Institute, Macaíba, Brazil
}

Submission: May 23, 2018; Published: June 01, 2018

\section{Opinion}

Sacral Neuromodulation (SN) is a therapy consisting of electrical stimulation of sacral nerves at S3 level delivered by a cylindrical electrode connected to a full-implantable neurostimulation device. SN in adult patients for urinary tract dysfunctions other than neurogenic modulates cortical and subcortical structures involved in urination, beside modulating structures with an important role in awareness of the rate of urination and filling of the bladder. A possible explanation for SN's therapeutic effect is due to the activation and inhibition of supraspinal brain areas by the spinal cord, which normalizes urinating functions. An important benefit of SN is that it is a minimally invasive and reversible treatment option, which includes a test phase before permanent implantation $[1,2]$.

Urinary dysfunctions related to neurological disorders frequently result in deterioration of the bladder and upper urinary tract, but there are few studies that report the effect of SN in such condition, and evidences of SN in children are even scarcer [3]. According to the International Children's Continence Society (ICCS), SN was primarily reported in treatment of patients with a non-neuropathic bladder, and safety and effectiveness were not established for children $<16$ years of age. Nonetheless, ICCS states the necessity of analyzing SN effects and efficacy in this specific population, given that the results of SN in children are still limited and it is still an investigative therapy alternative until this date [4].

Searching for studies using SN in pediatric neurogenic urinary tract dysfunction (NUTD) in Pubmed and Bireme databases, we found three articles, in which two of them evidenced the efficacy of SN diminishing urinary loss, number of diapers used in a day and urinary urgency, in addition to an increase in bladder complacency and capacity $[2,5]$.
Lippmann et al. reported the case of a 12-year-old girl with cerebral palsy and refractory neurogenicbladder, who was no longer evolving with conservative treatments. 16 months after implanting the electrode in S4 and beginning stimulation, there was an improvement in the patient's quality of life, which stopped wearing diapers and presented rare urinary loss. The authors suggested that further studies may identify suitable pediatric candidates for SN [2].

Guys et al. studied 42 children with spina bifida and neurogenic bladder, ages ranging from 5 to 21 years, during 12 months. Subjects were randomized and divided into two groups: the experimental group received treatment with sacral neuromodulation in S3 and the control group received conservative anticholinergic treatment. The experimental group presented improvements in bladder functional capacity and complacency, in addition to better intestinal transit. None of the patients in the control group reported subjective improvement [5].

In another study, Groen et al. Investigated,during 15 years, 18 children with ages from 9 to 17 years that received S3 neuromodulation implant. Among the subjects, five patients had NUTD in comorbidity with myelomeningocele, Guillain-Barré syndrome or anal atresia. In these 5 patients, only children with anal atresia and Guillain-Barré syndrome presented an improvement in urinary loss, by $90 \%$, and better urinary urgency. It was not observed any significant improvement with SN in three children with myelomeningocele. The authors stated that the diminished sample in their study does not allow for definitive conclusions on the efficacy of SN in the presented disorders but suggested that patients with incomplete neural disease may have a better outcome [6]. 
Additionally to criticism on the sampling number of such studies, Lippmann et al. presented another limitation regarding the size of the device, which has been designed for adults, and to the adaptation of the device over the years, since the child's growth can affect electrode positioning. In an attempt to minimize these effects, the lead wires were positioned deep enough to keep the electrodes out of the anterior surface of the sacral plaque. However, it is not possible to predict the migration that may occur due to skeletal growth [2]. Thus, additional studies are needed to follow the development of skeletal muscle development of the sacrum.

In all studies, children who had electrode migration related to tissue integration, defective connection, infection, and edema, removed the implant. Pain, reported as an adverse effect in adults, was not evidenced in these studies $[2,5,6]$. Early treatment in children with NUTD to prevent deterioration of the upper urinary tract is mandatory. However, since some conservative therapies may have their efficacy diminished after a certain period, implantation of the electrode for SN can be an alternative approach. Thus, SN effectiveness should be investigated in short and long-term, as well as the benefits and real risks for children with neurogenic bladder dysfunction.

\section{References}

1. Blok BFM, Jan Groen, Bosch JLHR, Veltman DJ, Lammertsma AA (2006) Different brain effects during chronic and acute sacral neuromodulation in urge incontinent patients with implanted neurostimulators. British journal of urology 98(6): 1238-1243.

2. Lippmann QK, Geller EJ (2013) Successful use of sacral neuromodulation in a 12-year-old with cerebral palsy and neurogenic bladder. Neuromodulation 17(4): 396-398.

3. Abello A, Das AK (2018) Electrical neuromodulation in the management of lower urinary tract dysfunction: evidence, experience and future prospects. Ther Adv Urol 10(5): 165-173.

4. Rawashdeh YF , Austin P, Siggaard C, Bauer SB, Franco I, et al. (2012) International children's continence society's recommendations for therapeutic intervention in congenital neuropathic bladder and bowel dysfunction in children. Neurourol Urodyn 31(5): 615-620.

5. Guys JM, Haddad M, Planche D, Torre M, Louis BC, et al. (2004) Sacral neuromodulation for neurogenic bladder dysfunction in children. J Urol 172(4 Pt 2): 1673-1676.

6. Groen LA, Hoebeke P, Loret N, Praet CV, Laecke EV, et al. (2012) Sacral neuromodulation with an implantable pulse generator in children with lower urinary tract symptoms: 15-year experience. J Urol 188(4): 13131318.
Creative Commons Attribution 4.0

International License

For possible submissions Click Here

\section{Submit Article}

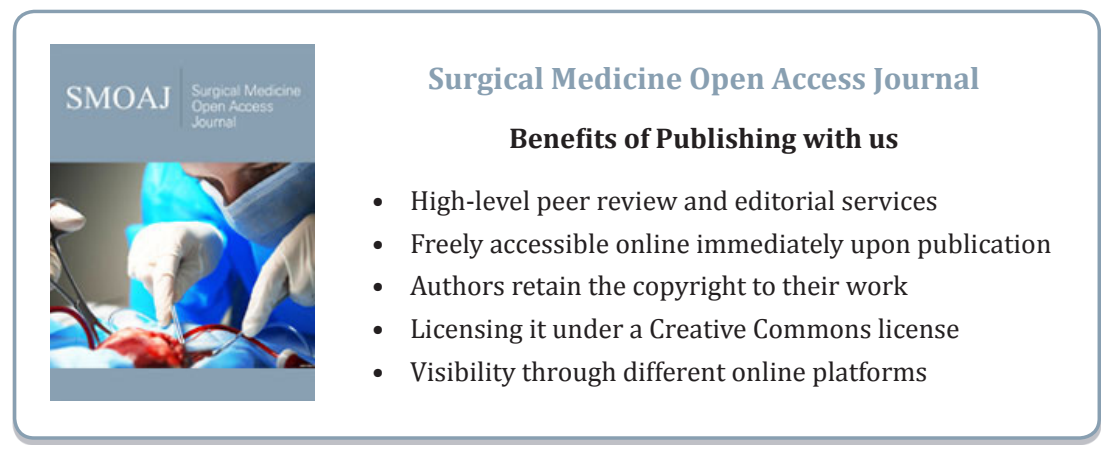

